\title{
Vasculitis of Vasa Vasorum and Aneurysm Formation in Kawasaki Disease: Predilection for Coronary Arteries Lesions
}

\author{
Zenshiro Onouchi ${ }^{1}{ }^{*}$, Akiko Hamaoka-Okamoto ${ }^{1}$, Chinatsu Suzuki ${ }^{1}$, Kenji Hamaoka ${ }^{1,2}$ \\ ${ }^{1}$ Department of Pediatrics, Kyoto Prefectural University of Medicine, Graduate School of Medical Science, Kyoto, Kyoto, Japan \\ ${ }^{2}$ Medical Center of Pediatric Cardiovascular Disease and Kawasaki Disease, Uji Tokushukai Hospital, Uji, Kyoto, Japan \\ Email address: \\ zen@mrj.biglobe.ne.jp (Z. Onouchi), ahamaoka@koto.kpu-m.ac.jp (A. Hamaoka-Okamoto), csuzuki@koto.kpu-m.ac.jp (C. Suzuki), \\ khamaoka@koto.kpu-m.ac.jp (K. Hamaoka) \\ ${ }^{*}$ Corresponding author
}

\section{To cite this article:}

Zenshiro Onouchi, Akiko Hamaoka-Okamoto, Chinatsu Suzuki, Kenji Hamaoka. Vasculitis of Vasa Vasorum and Aneurysm Formation in Kawasaki Disease: Predilection for Coronary Arteries Lesions. Cardiology and Cardiovascular Research. Vol. 5, No. 1, 2021 , pp. 7-15. doi: 10.11648/j.ccr.20210501.12

Received: November 21, 2020; Accepted: December 25, 2020; Published: January 15, 2021

\begin{abstract}
Backgrounds. The mechanism causing coronary artery lesions in Kawasaki disease (KD) has not yet been fully clarified. Objective. We hypothesized that the main coronary artery (MCA) segment perfused by the vasa vasorum (VV) arose from the atrial and ventricular branches of peripheral coronary arteries in the myocardium (Type $1 \mathrm{VV}$ externa) is more prone to aneurysm formation than that perfused by Type $2 \mathrm{VV}$ originated from the ostium. Methods and Results. We reviewed the coronary angiography and two-dimensional echocardiogram (2DE) data of KD patients in our hospital and measured the distances from the left coronary ostium to the proximal point of the aneurysm in the left MCA(D1) and to the MCA bifurcation (D2). We found that the ratio of the distances (D1/D2) was negatively correlated with the patients' age of KD onset, indicating that longitudinal extension of the left MCA aneurysms coincided with the development of Type 1 VV externa. We performed a literature review of KD cases with extracardiac aneurysms and found that 15 patients also had giant aneurysms in the MCA. Also, 8 of 9 extracardiac aneurysm cases whose clear 2DE images were available in the reports, the giant MCA aneurysms seemed to have developed at positions immediately adjacent to the ostium. We assume that the giant coronary aneurysms might be a consequence of the coincidence of aneurysms in the MCA segments perfused by Type 1 and $2 \mathrm{VV}$ externas and reflect a severe inflammation where Type $2 \mathrm{VV}$ externa which is less susceptible to blood flow reduction than Type $1 \mathrm{VV}$ externa is affected. Conclusions. Vasculitis in VV externa with the unique structure originating from and distributing most richly across coronary arteries might induce a vicious circle of hypoperfusion of $\mathrm{VV}$ externa and reduced coronary blood flow.
\end{abstract}

Keywords: Coronary Artery Aneurysm, Coronary Artery Ischemia, Coronary Blood Flow, Coronary Vasa Vasorum, Endothelial Dysfunction

\section{Introduction}

Kawasaki disease (KD) is a diffuse disease in the systemic vascular system affecting the venules and capillaries as well as the aorta with activation of the immune system [1] which is a central feature of KD [2]. The incidence of coronary artery aneurysm (CAA) in KD is $15-25 \%$ [3]. The foremost causes of death are CAA rupture, thrombotic occlusion, and chronic coronary insufficiency.

Degeneration of the endothelial cells in $\mathrm{KD}$ has been elucidated early on as primary lesion in blood vessels [4-7]. There are other reports on the development of coronary artery lesions [8-15].

Recently, Onouchi Y et al. analyzed susceptibility genes to $\mathrm{KD}$ and found ITPKC and CASP3 functional polymorphisms were associated with coronary artery aneurysm (CAA) formation [16-18].

The majority of research efforts for vascular lesions have focused on the inner and medial vascular layers (e.g., internal elastic lamina), which are, in fact, affected at the early stage of 
vascular lesions.

In our autopsy case with ruptured aneurysm of the left main coronary artery in $\mathrm{KD}$, the pathogenesis of coronary aneurysm formation was ascribed to the vasa vasorum vasculitis, resulting in the hypoxia and necrosis of the host vessel [19, 20].

Indeed, experimental manipulation of the adventitia and, more specifically, of the vasa vasorum (VV) could lead to medial edema, degeneration, and ischemic necrosis, followed by later intimal thickening due to proliferation of smooth muscle cells and VV proliferation [21-25]. Moreover, hypoperfusion of the adventitial $\mathrm{VV}$ develops an abdominal aortic aneurysm [26].

Clarke reported two types of $\mathrm{VV}$ externa in the coronary artery [27]. One is Type $1 \mathrm{VV}$ externa originating from atrial and ventricular branches of peripheral coronary arteries in the myocardium and develops toward the ostium along the main coronary artery (MCA) during childhood [28]. Kwon HM et al. [29] described that the VV externa of pigs runs longitudinally along vessel walls from coronary branch points. The other (what we refer to as Type $2 \mathrm{VV}$ externa) originates from the coronary ostium and grows toward the coronary artery's proximal portion within about $1 \mathrm{~cm}$ from the ostium before reaching adulthood [27].

This study aimed to elucidate the association of vasculitis of vasa vasorum and aneurysm formation in the host vessel.

\section{Background}

We hypothesized that potential heterogeneities in the structure, development and spatial density of the adventitial VV among different vascular beds may be an underlying mechanism of the different frequencies of aneurysm formation and that VV vasculitis causes hypoperfusion most severely on the aorta and medium-sized arteries.

\section{Methods}

\subsection{Distance Ratio}

We studied whether the longitudinal extension of the left main coronary artery (LMCA) aneurysm coincided with the development of the VV externa (here named as Type $1 \mathrm{VV}$ externa) (Figure 1).

Subjects: we retrospectively analyzed data from patients treated at our university hospital over 19-year periods from 1972 to 1980 and 1988 to 1999 . We included KD patients with CAA in the LMCA.

Coronary angiograms and two-dimensional echocardiogram (2DE) images were analyzed. We measured the distances from the left coronary ostium to both the proximal point of the aneurysm in the LMCA (D1) and its bifurcation point (D2) (Figure 2). We defined the distance ratio as $y=\mathrm{D} 1 / \mathrm{D} 2 \times 100$, and assessed the correlation between the distance ratio and ages either at KD onset or the coronary imaging. We evaluated the correlation between the distance ratio and (A) the day of illness when the patients underwent coronary angiography or echocardiography or (B) the patients' age at KD onset.

A single regression test was performed to analyze the linear correlations between the two parameters by using Microsoft Excel. Statistical significance was set at a $P$ value $<0.05$.

\subsection{A Literature Review of KD Cases with Extracardiac Aneurysm}

Sometimes, aneurysms of arteries other than coronary arteries, i.e., iliac and axillary arteries, are seen in KD. VV perfuses such arteries has a similar structure to Type $2 \mathrm{VV}$ externa. Considering that vasculitis of Type $1 \mathrm{VV}$ is more likely to cause ischemic necrosis and damage coronary arteries than Type $2 \mathrm{VV}$, we hypothesized that KD cases with extracardiac aneurysms had severer vascular inflammation than those without. We also hypothesized that the vasculitis of Type $2 \mathrm{VV}$ externa could cause aneurysms in its perfusing LMCA region when the inflammation is highly severe, and the giant aneurysms neighboring the ostium are the consequences of the fusion of aneurysms in LMCA areas perfused by Type1 and $2 \mathrm{VV}$ externa. To investigate the comorbidity of coronary and extracardiac aneurysms in KD patients, we conducted a literature search for previous reports in 1983 - 2016 in PubMed. We also searched case reports of extracardiac aneurysms in the 'A Bibliography of KAWASAKI DISEASE' distributed by the Japan Kawasaki Research Center. The papers of extracardiac aneurysm cases with clear 2DE images of their coronary arteries were then selected.

This study conformed to the Declaration of Helsinki principles.

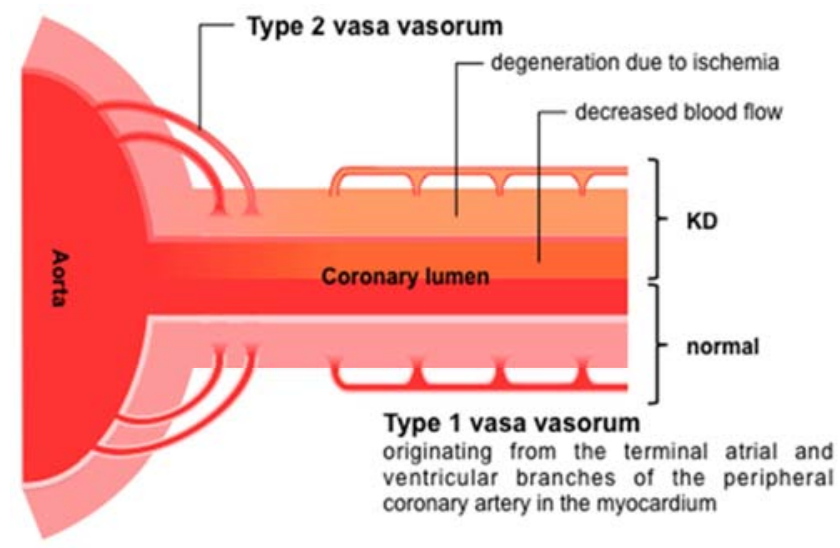

Figure 1. Two-dimensional imaging of the aorta and LMCA An illustration of the origins and running course of VVs of the main coronary arteries described by Clarke et al. [27]. The upper half represents KD with the decrease of coronary blood flow and the medial edema and degeneration in the coronary artery. Type $1 \mathrm{VV}=$ vasa vasorum externa originating from atrial and ventricular branches of peripheral coronary arteries, and Type $2 \mathrm{VV}=\mathrm{vasa}$ vasorum externa arising from the ostium. 


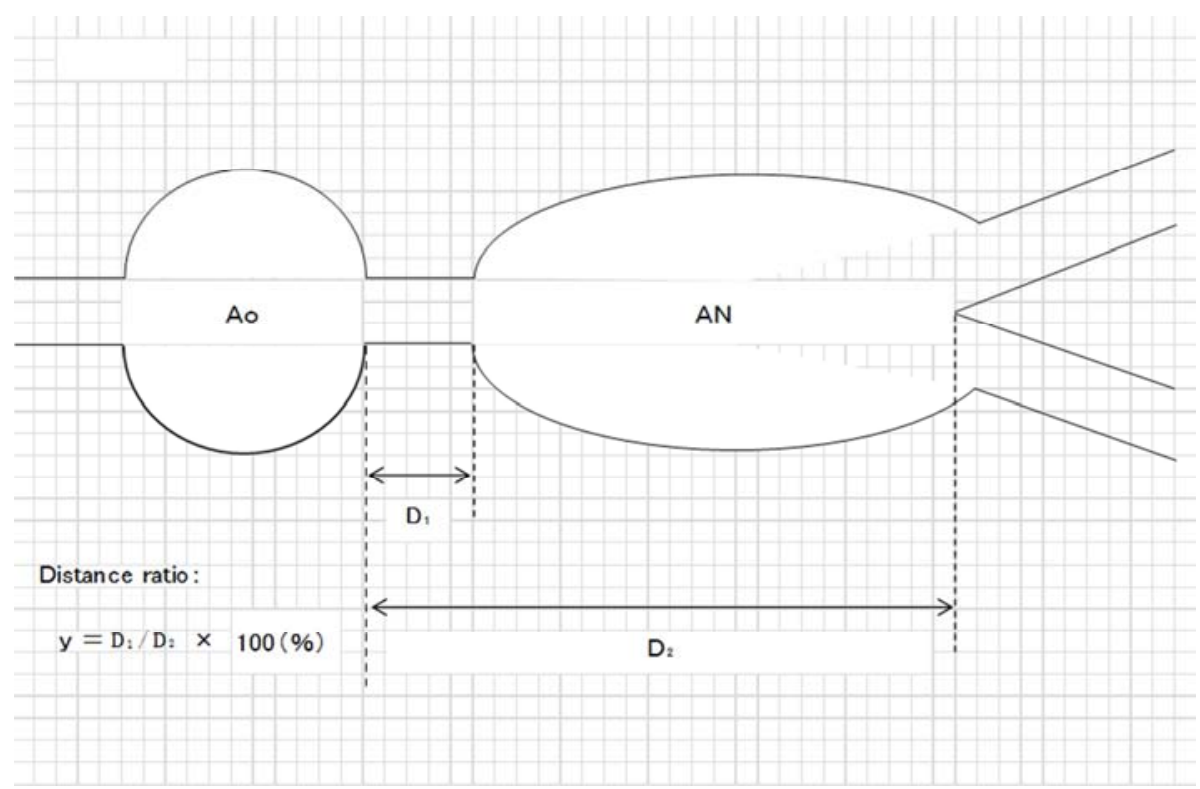

Figure 2. Imaging of an aneurysm in the LMCA and the calculation of the distance ratio Illustration of the calculation for the Distance ratio of an aneurysm in the coronary arteriograms and $2 D E$ images. $A o=a$ arta, $A N=$ aneurysm.

\section{Results}

\subsection{Distance Ratio}

Sufficient data were available for analysis of coronary artery images in all 63 cases without extracardiac aneurysms. Mean age at KD onset $(x)$ was 2 years 6 months (median, 1 year 3 months old; range, 2 months to 7 years 5 months). Mean age at the time of angiography or echocardiography was 5 years 7 months old (median, 2 years 6 months; range, 1 month to 36 years 6 months). The distance ratio $(y)$ was negatively correlated with age $(x)$ at $\mathrm{KD}$ onset but was not correlated with age at the time of angiography or echocardiography (Figure 3). The linear regression equation was as follows: $y=47.634-2.775 x(\mathrm{P}=0.008, \mathrm{R}=0.326)$.

\subsection{Extracardiac Aneurysm Is Associated with the Giant CAA}

Except for cases without descriptions about CAA, all 73 patients with extracardiac aneurysms from the literature revealed an LMCA aneurysm. At KD onset, the median age was 4 months in the 51 male patients (range, 7 weeks to 6 years) and 22 female patients (range, 4 weeks to 3 years 5 months). There were 15 cases with descriptions of giant coronary aneurysms in the reports. Among them, clear images of LMCA were available for 9 patients for assessment (Table 1).

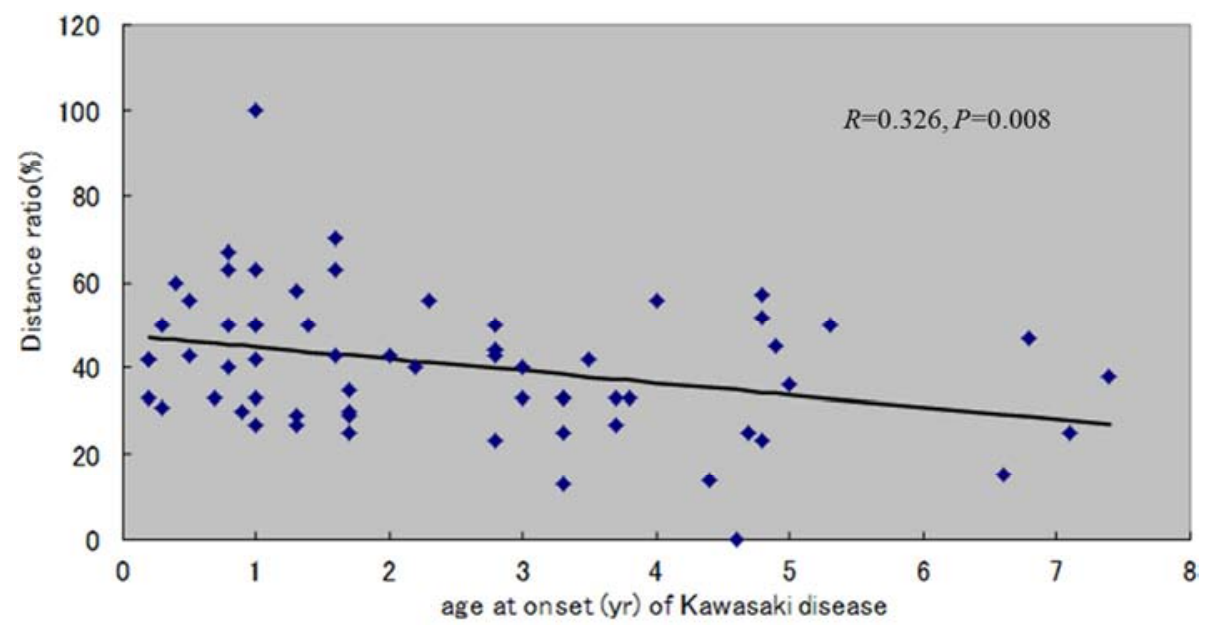

Figure 3. Relation between the distance ratio and the age at KD onset Plots of the relation between Distance ratio of aneurysm (\%) and age at onset (yr) of Kawasaki disease in the 63 patients. The Distance ratio of the LMCA aneurysm is negatively correlated with the age at KD onset.

The male-to-female ratio of the 9 cases was 7: 2. The median day at the time of angiography or echocardiography after KD onset was more than 3 months (range, 1.7 months to 1 year 4 months).
Eight of 9 coronary artery aneurysms were located immediately after the ostium (Figure 4). The remaining one was located at a short distance from the ostium, probably resulting from the regression of aneurysm [30]. 
Table 1. Extracardiac aneurysm with Kawasaki disease.

\begin{tabular}{|c|c|c|c|c|c|}
\hline No. & Age at onset of KD & Sex & Distance from coronary ostium to AN & DI at coronary angiography & Extracardiac AN \\
\hline 1 & $3 \mathrm{y} 3 \mathrm{~m}$ & M & No description & & R. axillary artery \\
\hline \multirow[t]{3}{*}{2} & $5 \mathrm{~m}$ & $\mathrm{~F}$ & No description & & Distal abdominal \\
\hline & & & & & aorta- Bil. common \\
\hline & & & & & iliac arteries \\
\hline \multirow[t]{6}{*}{3} & $2 \mathrm{y} 4 \mathrm{~m}$ & $\mathrm{~F}$ & Immediately after & $7 \mathrm{~m}$ & Distal abdominal \\
\hline & & & & & aorta \\
\hline & & & & & Bil. femoral arteries \\
\hline & & & & & R. axillary artery \\
\hline & & & & & Bil. common iliac \\
\hline & & & & & arteries \\
\hline 4 & $1 \mathrm{y}$ & M & Indistinct immage & $4 \mathrm{~m}$ & Bil. axillary arteries \\
\hline \multirow[t]{2}{*}{5} & $2 \mathrm{y} 1 \mathrm{~m}$ & M & Immediately after & $>75 \mathrm{~d}$ & $\begin{array}{l}\text { Bil. common iliac } \\
\text { arteries }\end{array}$ \\
\hline & & & & & L. internal iliac artery \\
\hline 6 & $1 \mathrm{y} 1 \mathrm{~m}$ & $\mathrm{~F}$ & Immediately after & $>50 \mathrm{~d}$ & Bil. Axillary arteries \\
\hline \multirow[t]{3}{*}{7} & $4 \mathrm{~m}$ & M & Immediately after & $3 \mathrm{~m}$ & Bil. axillary arteries \\
\hline & & & & & Bil. internal iliac arteries \\
\hline & & & & & Abdominal aorta \\
\hline \multirow[t]{2}{*}{8} & $8 \mathrm{~m}$ & M & Gap* & $>6 \mathrm{~m}$ & R. axillary artery \\
\hline & & & & & Bil. common iliac arteries \\
\hline \multirow[t]{2}{*}{9} & $11 \mathrm{~m}$ & M & Immediately after & $2 \mathrm{~m}$ & Bil. axillary arteries \\
\hline & & & & & Bil. common iliac arteries \\
\hline \multirow[t]{2}{*}{10} & $2 \mathrm{y} 5 \mathrm{~m}$ & M & Immediately after & $3 \mathrm{~m}$ & Bil. axillary arteries \\
\hline & & & & & Bil. common iliac arteries \\
\hline \multirow[t]{3}{*}{11} & $2 \mathrm{~m}$ & M & Indistinct immage & $2 \mathrm{~m} \mathrm{22d}$ & Bil. axillary arteries \\
\hline & & & & & Ascending aorta \\
\hline & & & & & Abdominal aorta \\
\hline \multirow[t]{2}{*}{12} & $2 \mathrm{~m}$ & M & Indistinct immage & $3 \mathrm{~m} 18 \mathrm{~d}$ & Bil. axillary arteries \\
\hline & & & & & Abdominal aorta \\
\hline \multirow[t]{4}{*}{13} & $4 m$ & M & Immediately after & $1 \mathrm{y} 4 \mathrm{~m}$ & Bil. axillary arteries \\
\hline & & & & & Abdominal aorta \\
\hline & & & & & Bil. common iliac arteries \\
\hline & & & & & Bil. internal iliac arteries \\
\hline \multirow[t]{2}{*}{14} & $2 \mathrm{~m}$ & M & Immediately after & $2 \mathrm{~m} \mathrm{16d}$ & Bil. axillary arteries \\
\hline & & & & & L. subclavian artery \\
\hline \multirow[t]{2}{*}{15} & $1 \mathrm{~m} 19 \mathrm{~d}$ & M & No discription & $6 \mathrm{~m}$ & Gangren of 4 toes of the \\
\hline & & & & & left foot \\
\hline
\end{tabular}

KD: Kawasaki disease, AN; aneurysm, DI; day of the illness, m; month, d; day, R; right, Bil; bilateral, L; left

(1) Shoni Geka Naika, Jpn J Pediatr Surg Med 5: 235-241

(2) Shoni Geka Naika, Jpn J Pediatr Surg Med 8: 119-125

(3) Pediatr 1981; 68: 885-888

(4) Shonika Rinsho, Jpn J Pediatr 34: 547-551.

(5) Shonika Rinsho, Jpn J Pediatr 36: 1237-1242.

(6) Shonika Rinsho, Jpn J Pediatr 36: 1237-1242.

(7) Shonika Shinryo, J Pediatr Practice 47: 1992-2003.

(8) Rinsho Shoni Igaku, Jpa J Pediatr (Sapporo). 32: 355-360.

(9) Kita Kanto Igaku, Kitakanto Med J 38: 365-370.

(10) Kita Kanto Igaku, Kitakanto Med J 38: 365-370.

(11) Nippon Shonika Gakkai Zasshi, J Jpn Pediatr Soc 93: 292-297.

(12) Nippon Shonika Gakkai Zasshi, J Jpn Pediatr Soc 93: 292-297.

(13) Shonika Rinsho, Jpn J Pediatr 44: 2049-2054.

(14) Shonika Rinsho, Jpn J Pediatr 48: 454-458.

(15) Clinical Pediatr 2007; 46: 345-348. 


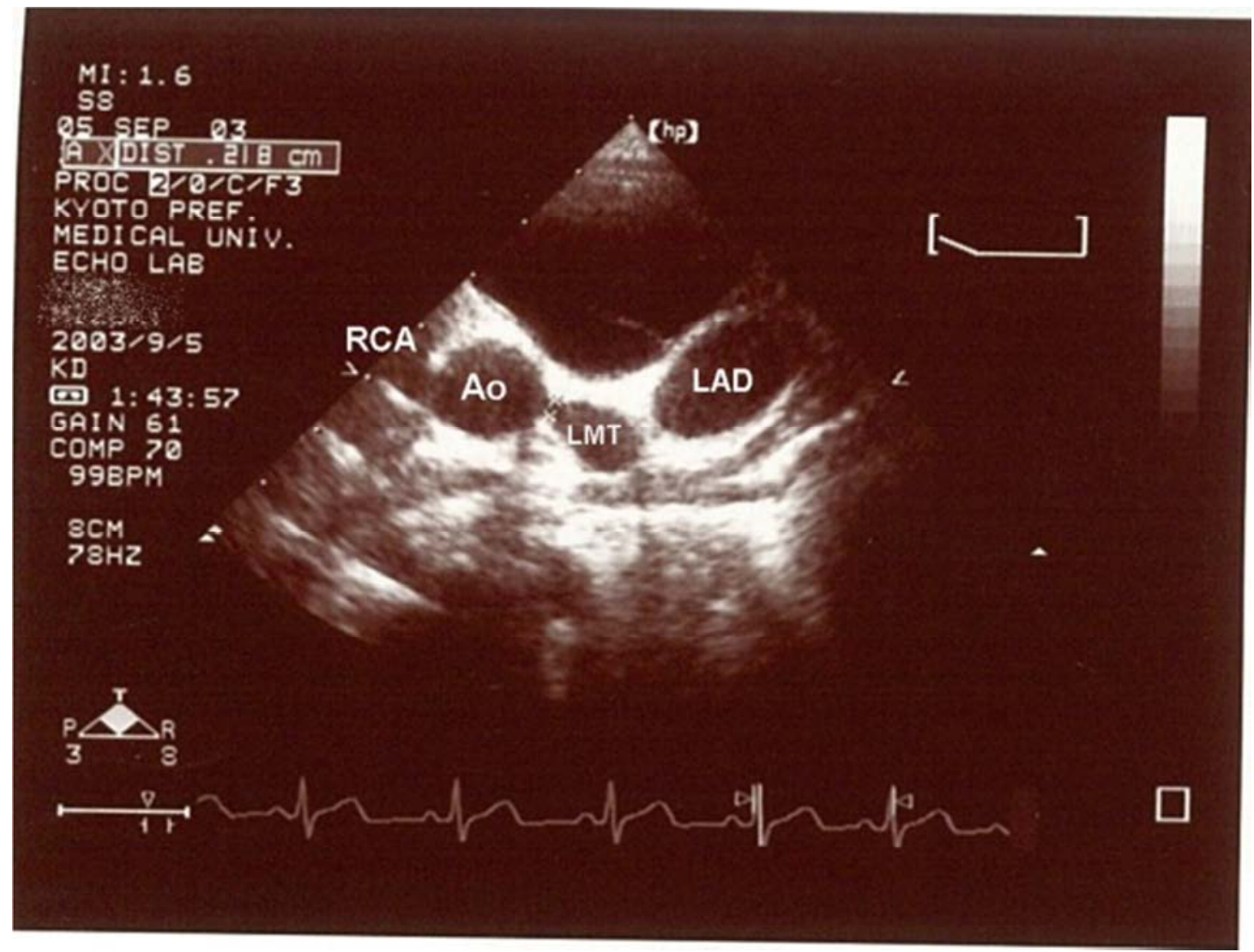

Figure 4. Two-dimensional echocardiogram of the patient with an extracardiac aneurysm An ilustration of $2 D E$ of our 1.6 year old patient with extracardiac aneurysm. This echocardiogram shows giant aneurysms proximal to both coronary ostia, combined with a giant aneurysm in the LAD. Ao=aorta, LMT $(L M C A)=$ left main trunk, LAD=left anterior descending artery, $R C A=$ right coronary artery.

\section{Discussion}

Fujiwara described that the vascular inflammation in KD first takes place as perivasculitis and vasculitis on microvessels (arterioles, venules, and capillaries) and small arteries including VV of three MCAs [1]. In the MCAs, acute perivasculitis, inflammation of the adventitia, and acute endarteritis were observed, but inflammatory changes of the media were not detected in the early stage. The inflammatory tissue was edematous and infiltrated chiefly with neutrophils, eosinophils, and lymphocytes. They insisted that the origin of angiitis exists in the microvessels.

Amano $\mathrm{S}$ et al. [4] demonstrated that the arteries' primary lesions were intimal endothelial degeneration and increased vascular permeability. They also pointed out the degeneration of the VV's endothelial cells and infiltration of the small or moderate number of lymphocytes, large mononuclear cells, and neutrophils. Subendothelial accumulation of mononuclear cells followed by the VV vasculitis, periarteritis, and inflammation of adventitia was observed [31]. Landing et al. [32] described that the inflammation of the coronary arteries begins at the adventitia.

Neutrophils activated by G-CSF, TNF-alpha, and GM-CSF adhere to damaged endothelium [33]. Adherent factor changes and both mononuclear cells and macrophages massively gather to the endothelium. ICAM-1 and CD 44 [34] mediate to transmigrate them into the media through the endothelium.
Neutrophils produce massive ROS [35] and cause endothelial damage in $\mathrm{KD}$ [36]. In the early stage in $\mathrm{KD}$, activated by the proinflammatory cytokine [15], neutrophils adhere to the endothelial cells and secrete MRP-8, 14 and induce the thrombogenic and inflammatory reaction on the endothelial cells of the microvessels [37].

Proinflammatory cytokines are massively produced in KD. Monocytes/macrophages secrete TNF, which is an important predisposing factor [38]. Furthermore, proinflammatory cytokine directly causes endothelial damage.

Neutrophils express VEGF isoforms only in the early stage of acute KD [9], whereas mononuclear cells express VEGF isoforms predominantly at 2-4 wk after onset [14]. VEGF has been considered to be one of the mediators of microvascular permeability in KD [9]. Mononuclear cells which acceleratory express VEGF, massively infiltrate at the intima of the coronary arteries in 10 to 12 days of illness.

Oxygen and nutrients are supplied to inner thirds of media through luminal endothelium, and adventitia to middle thirds of media through VV externa in the mammalian vessel wall $[39,40]$. Infiltration of the cells in the early stage of KD more severe in the adventitia than the intima [41].

These observations suggested the difference of perfusions from VV in the adventitia and luminal endothelium [42].

Hypoperfusion of the media due to reduced blood flow associated with VV vasculitis with the thrombotic obstruction [37] induces hypoxia. Hypoxia triggers HIF-1alfa and VEGF 
secretion from smooth muscle cells of the media [43], resulting in VV proliferation. VEGF has been identified as a cytokine that regulates differentiation, proliferation, migration, and survival of cells in the microvascular endothelium $[41,44]$. These characteristics are important since they imply that the VV may regulate their tone and vascular perfusion in a manner similar to small coronary arteries, as was demonstrated by Scotland et al. [40, 45]. It seems possible that, due to reduced transendothelial permeation, infection, inflammation or thrombosis, the smooth muscle tone of proximal vasa vasorum is selectively increased and results in blood flow reduction and hypoxia [39].

In acute $\mathrm{KD}$, the migration and proliferation of endothelial cells have been demonstrated to be markedly enhanced by cytokines $[46,47]$. Inflammatory cells accumulate at damaged endothelium and degrade basement membrane [48], resulting in the dissemination of inflammatory cells and substances into the media. Thus inflammation in the media is induced and, combined with hypoxia and ischemic necrosis, leads to the cytokine storm and necrotizing panarteritis [4]. We consider that reduced blood flow of the atrial and ventricular branches of the coronary artery, selective blood flow reduction in proximal VV [45], local hypoxia in the media by insufficient oxygen supply [4, 19], dissemination of inflammatory cells and substances, and cytokine storm and necrotizing panarteritis [4] sequentially occur.

Earlier work defined two general subsets of $\mathrm{CD}^{+} \mathrm{T}$ lymphocytes, Th1 and Th2, determined by the relative activity of two members of the signal transducer and activator of transcription (STAT) family of proteins, STAT4 and STAT6, respectively. In turn, the relative activity of STAT4 versus STAT6 is determined by the prevailing cytokine milieu (Ramagnani, 2006). Th1 cells secrete proinflammatory cytokines, for example, IL-2, IL-12, IFNgamma, and TNFalfa, whereas $\mathrm{Th} 2$ cells secrete primarily anti-inflammatory cytokines.

Among them, T lymphocytes remarkably activated due to SNP of ITPKC gene [16] may play a pivotal role in the necrotizing panarteritis in the media of KD.

CAL is the most severe and the most frequent in the cardiovascular lesions of KD. However, the reason of preference for the coronary arteries remains to be clarified. Histopathologic changes similar to the coronary arteries are also often observed in the aorta and medium-sized arteries with VV in KD [49]. However, aneurysms develop more commonly in the coronary arteries [50].

Coronary arteries have the highest VV density among different vascular beds [51], which indicates that the coronary artery wall demands much oxygen. Because having 70 times higher endothelial surface area than luminal endothelium [51], endothelial dysfunction in the VV level might impact vascular wall perfusion more than luminal endothelial dysfunction of the host vessel. We considered endothelial dysfunction in the $\mathrm{VV}$ vasculitis in the developing MCA of infants and young children may promptly lead to depression of oxygen and nutrients supply to the MCA.

\section{Distance ratio}

The distance ratio was negatively correlated with age at KD onset. Type $1 \mathrm{VV}$ externa arises from the point of MCA bifurcation and develops longitudinally toward the ostium [27, 29]. In a previous study by Clarke, VVs of coronary arteries were investigated among children older than 3years old [27]. However, VVs in the MCA were observed in infants and young children $[19,52]$. VV is assumed to play a central role in the oxygen and nutrients supply to the MCA wall. Vasculitis of Type $1 \mathrm{VV}$ externa might lead to blood flow reduction and then hypoxia in the adventitia and media of the MCA. Additional effects of inflammatory cell infiltration might cause necrosis and aneurysm formation.

Thus, we consider that the longitudinal sizes of the LCMA aneurysms reflect the length of Type $1 \mathrm{VV}$ externa.

Extracardiac aneurysms were associated with giant CAAs.

Amano et al. [53] studied the distribution of the vascular lesions in $\mathrm{KD}$ and noted aneurysms were observed in the aorta and medium-sized arteries with VV. On the other hand, inflammation was observed in the intima but not in the adventitia of interlobaris denis which have no VV [54].

Because of the structural difference from Type $1 \mathrm{VV}$ externa of LMCA, blood flow in the VVs of the aorta and extracardiac arteries is not easy to reduce at $\mathrm{VV}$ vasculitis. Therefore, it might be possible that KD cases with extracardiac aneurysms might have much severer systemic inflammation in the acute phase, and arteries perfused by Type $2 \mathrm{VV}$ were also affected. Results of the literature review in this study that all extracardiac aneurysm cases had CALs are supporting this idea. Ichinose et al. described [55] that giant aneurysms developed as a consequence of a merge of usual-sized CALs formed proximally each other. The finding that the beginning of the giant aneurysms was in the vicinity of the ostium also supports our hypothesis of the genesis of giant aneurysms.

As aforementioned, Type $1 \mathrm{VV}$ externa arises from the atrial and ventricular branches of the peripheral coronary arteries, supplying oxygen and nutrients to the media's outer thirds. Therefore, the supply of oxygen and nutrients to the coronary artery wall is greatly influenced by the coronary artery function itself.

Ritman et al. [39] and Scotland et al. [40] described that endothelial dysfunction and an increased vascular tone of the VV may be enhanced due to inflammation and the reduced bioavailability of nitric oxide, secondary to the increase in endogenous oxidative stress.

VV arteritis is considered to result from continuous extension of vasculitis of peripheral coronary arteries, or to be a part of the generalized vasculitis of the arterioles and small arteries in the early stage of KD [1] or both. We propose a pathogenesis scheme on a predilection for CALs in KD (Figure 5): the vicious circle of blood flow reduction between coronary arteries and the VV. 
Richest WV density

Functions of $\mathrm{W}$ as endoarteries

by the compressive forces
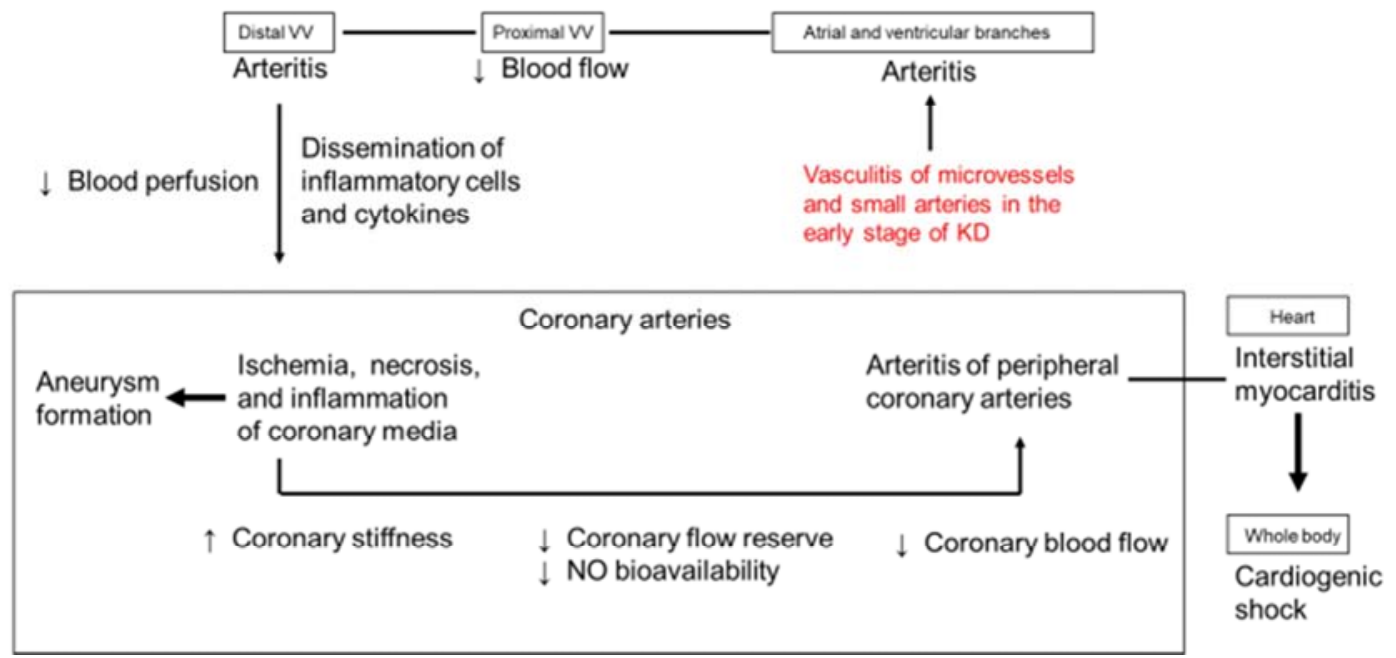

Figure 5. Vicious circle.

VV vasculitis

$\downarrow$

VV blood flow $\downarrow \rightarrow$ hypoxia in the media $\rightarrow$ stiffness of epicardial coronary artery $\downarrow \rightarrow$

Coronary blood flow $\downarrow \rightarrow$ peripheral coronary flow $\downarrow \rightarrow$ blood flow of atrial and

Ventricular branches $\downarrow \rightarrow$ VV blood flow $\downarrow \rightarrow$

Medial degeneration and necrosis, resulting in the increased stiffness, may attribute to insufficient oxygen and nutrients supply due to the VV vasculitis. Previously, we reported a decrease of coronary reserve in patients with CALs [56]. We considered that the observation was a consequence of increased vascular resistance of peripheral coronary arteries. Now we are assuming that increased stiffness of the epicardial coronary artery due to the increased oxidative stress may also contribute to the phenomenon.

A recent study has further provided evidence that local oxidative stress, as assessed by net production of isoprostanes across the LAD artery territory, has a role in the reduction of nitric oxide bioavailability to humans with coronary endothelial dysfunction [57].

Study limitation

Many of the giant coronary aneurysm cases in this study were those affected with KD when 2DE had not become popular. Therefore, for these patients, a relatively long time since the onset of KD had elapsed when 2DE was conducted. In some patients, aneurysms might have regressed, and the regression could be supposed to weaken the correlation between the distance ratio and the patients' age.

Furthermore, although we proposed ischemic necrosis in the arterial wall as the pathogenesis of aneurysms in KD, we could not obtain direct experimental evidence in hypoxic condition in the vascular wall. We reported the low incidence of aneurysm formation in patients with neutropenia in KD and proposed granulopoiesis for treatment of KD [58].

Research into the biology of ischemia or ischemia/perfusion injury has increased in recent years [59]: consequently, many therapeutic strategies have been proposed [60-63].

\section{Conclusions}

Coronary arteries liable to aneurysms in $\mathrm{KD}$ have the highest VV density, indicating their higher oxygen and nutrients requirement. VV dysfunction might predispose oronary arteries to hypoxia in the media.

The role of $\mathrm{VV}$, the vicious circle between coronary arteries and their VV, intra- and intervascular heterogeneity of the vascular bed, and the strength of the systemic inflammation might be a determinant of the difference in the coronary outcome in KD.

\section{Acknowledgements}

We gratefully acknowledge Dr. Setsuya Fujita, Professor Emeritus of the Department of Pathology, Kyoto Prefectural University of Medicine, for advice and support.

Our gratitude is due to our colleagues in the Department of Pediatrics for laboratory examination of angiocardiography.

\section{References}

[1] Fujiwara H, Hamashima Y. Pathology of the heart in Kawasaki disease. Pediatrics 1978; 61: 100-107.

[2] Burns JC, Glodé MP. Kawasaki disease. Lancet 2004; 364 : 533-544. 
[3] Kato H, Sugimura T, Akagi T, Sano N, Hashino K, Maeno Y, et al. Long-term consequences of Kawasaki disease. A 10- to 21-year follow-up study of 594 patients. Circulation 1996; 94 : $1379-1385$.

[4] Amano S, Hazama F, Hamashima Y. Pathology of Kawasaki disease. I. Pathology and morphogenesis of the vascular changes. Jpn Circulation J 1979; 43: 633-643.

[5] Terai M, Kohno Y, Niwa K, Umemiya T, Mikata A, Nakajima $\mathrm{H}$. Imbalance among circulating $\mathrm{T}$ cell subsets and staining from HLA-DR antigen in coronary endothelial cells in Kawasaki disease. [Arerugi], Jpn J Allergol 1987; 36: 394-403.

[6] Sato N, Sagawa K, Sasaguri Y, Inoue O, Kato H. Immunopathology and cytokine detection in the skin lesions of patients with Kawasaki disease. J Pediatr 1993; 122: 198-203.

[7] Nagata, S, Yamashiro Y, Maeda M, Ohtsuka Y, Yabuta K. Immuno- histochemical studies on small intestinal mucosa in Kawasaki disease. Pediatr Res 1993; 33: 557-563.

[8] Terai M, Honda T, Yasukawa K, Higashi K, Kohno Y. Prognostic impact of vascular leakage in acute Kawasaki disease. Circulation 2003; 108: 325-330.

[9] Yasukawa K, Terai M, Shulman ST, Toyozaki T, Yajima S, Kohno Y, et al. Systematic production of vascular endothelial growth factor and fms-like tyrosin-kinase 1 receptor in acute Kawasaki disease. Circulation 2002; 105: 766-769.

[10] Senzaki H, Kobayashi T, Nagasaka H, Nakano H, Kyo S, Yokote Y, et al. Plasminogen activator inhibitor-1 in patients with Kawasaki disease: diagnostic value for the prediction of coronary artery lesion and implication for a new mode of therapy. Pediatr Res 2003; 53: 983-988.

[11] Furui J, Ishii M, Ikeda H, Muta H, Egami K, Sugahara Y, et al. Soluble forms of the selectin family in children with Kawasaki disease: predilection for coronary lesions. Acta Pediatr 2002; 91: 1183-1188.

[12] Kariyazono H, Ohno T, Khajoee V, Ihara K, Kusuhara K, Kinukawa N, et al. Association of vascular endothelial growth factor (VEGF) and VEGF receptor polymorphisms with coronary artery lesions of Kawasaki disease. Pediatr Res 2004; 56: 953-959.

[13] Furuno K, Takada H, Yamamoto K, Ikeda K, Ohno T, Khajoee $\mathrm{V}$, et al. Tissue inhibitor of metalloproteinase 2 and coronary artery lesions in Kawasaki disease. J Pediatr 2007; 151: 155-160.

[14] Hamamichi Y, Ichida F, Yu X, Hirono K, Uese KI, Hashimoto I, et al. Neutrophil and mononuclear cells express vascular endothelial growth factor in acute Kawasaki disease: its possible role in progression of coronary artery lesions. Pediatr Res 2001; 49: 74-80.

[15] Suzuki H, Noda E, Miyawaki M, Takeuchi T, Uemura S, Koike M. Serum levels of neutrophil activation cytokines in Kawasaki disease. Pediatr Int 2001; 43: 115-119.

[16] Onouchi Y, Gunji T, Burns JC, Shimizu C, Newburger JW, Yashiro M, et al. ITPKC functional Polymorphism associated with Kawasaki disease susceptibility and formation of coronary artery aneurysms Nature Genetics 2008; 40: 35-42.

[17] Onouchi Y, Ozaki K, Burns JC, Shimizu C, Hamada H, Honda $\mathrm{T}$, et al. Common variants in CASP 3 confer susceptibility to Kawasaki disease. Hum Mol Genet 2010; 19: 2898-2906.
[18] Onouchi Y, Ozaki K, Burns JC, Shimizu C, Terai M, Hamada $\mathrm{H}$, et al. A genome-wide association study identified three new risk loci for Kawasaki disease Nature Genetics 2012; 44: 517-521.

[19] Tanaka K, Onouchi Z, Tomizawa M, Goto M, Kinpara S, Kusunoki T, et al. A study of Kawasaki disease. Part 2. A presentation of an autopsy case and relationship with infantile periarteritis nodosa [Nippon Shonika Gakkai Zasshi], J Jpn Pediatr Soc 1973; 77: 397-411.

[20] Onouchi Z, Tomizawa N, Goto M, Nakata K, Fukuda M. Cardiac involvement and prognosis in acute mucocutaneous lymph node syndrome Chest 1975; 68: 297-301.

[21] Booth RF, Martin JF, Honey AC, Hassall DC, Beesley JE, Moncada S. Rapid development of atherosclerotic lesions in the rabbit carotid artery induced by perivascular manipulation. Atherosclerosis 1989; 76: 257-268.

[22] Barker SG, Tilling LC, Miller GC, Beesley JE, Fleetwood G, Stavri GT, Baskerville PA, Martin JF. The adventitia and atherogenesis: removal initiates intimal proliferation in the rabbit which regresses on generation of a 'neoadventitia'. Atherosclerosis 1994; 105: 131-144.

[23] Nakata T, Shionoya S. Vascular lesions due to obstruction of the vasa vasorum. Nature $1966 ; 212: 1258-1259$.

[24] Martin JF, Booth RFG, Moncada S. Arterial wall hypoxia following hyperfusion through the vasa vasorum is an initial lesion in atherosclerosis. Eur J Clin Invest 1990; 20: 588-592.

[25] Barker SGE, Talbert A, Cottam S, Baskerville PA, Martin JF. Arterial intimal hyperplasia after occlusion of the adventitial vasa vasorum in the pig. Arterioscler Thromb 1993; 13: 70-77.

[26] Wilcox JN, Scott NA. Potential role of the adventitia in arteritis and atherosclerosis Int J Cardiol 1996; 54: S21-35.

[27] Clarke JA. An X-ray microscopic study of the vasa vasorum of normal human coronary arteries. J Anat 1964; 98: 539-543.

[28] Clarke JA. An X-ray microscopic study of the postnatal development of the vasa vasorum of normal human coronary arteries. Acta Anat (Basel) 1966; 64: 506-516.

[29] Kwon HM, Sangiorgi G, Ritman EL, McKenna C, Holmes DR Jr, Schwartz RS, et al. Enhanced coronary vasa vasorum neovascularization in experimental hypercholesterolemia. J Clin Invest 1998; 101: 1551-1556.

[30] Tanaka N, Naoe S, Masuda H, Ueno T. Pathological study of sequelae of Kawasaki disease (MCLS). With special reference to the heart and coronary arterial lesions. Acta Pathol Jpn 1986; 36: 1513-1527.

[31] Jennette JC. Implications for pathogenesis of patterns of injury in small- and medium-sized-vessel vasculitis. Cleve Clin J Med 2002; 69: S11 33-38.

[32] Landing BH, Larson EJ. Are infantile periarteritis nodosa with coronary artery involvement and fatal mucocutaneous lymph node syndrome the same? Comparison of 20 patients from North America with patients from Hawaii and Japan. Pediatrics 1977; 59: 651-662.

[33] Igarashi H, Hatake K, Tomizuka H, Yamada M, Gunji Y, Momoi MY. High serum levels of M-CSF and G-CSF in Kawasaki disease. Br J Haematol 1999; 105: 613-615. 
[34] Xu H, Manivannan A, Jiang HR, Liversidge J, Sharp PF, Forrester JV, et al. Recruitment of IFN-gamma-producing (Th1-like) cells into the inflamed retina in vivo is preferentially regulated by $\mathrm{P}$-selectin glycoprotein ligand 1: $\mathrm{P} / \mathrm{E}$-selectin interactions. J Immunol 2004; 172: 3215-3224.

[35] Rodrigues SF, Granger DN. Role of blood cells in ischemia-reperfusion induced endothelial barrier failure. Cardiovasc Res 2010; 87: 291-299.

[36] Niwa Y, Sohmiya K. Enhanced neutrophilic functions in mucocutaneous lymph node syndrome, with special reference to the possible role of increased oxygen intermediate generation in the pathogenesis of coronary thromboarteritis. J Pediatr 1984; 104: 56-60.

[37] Viemann D, Strey A, Janning A, Jurk K, Klimmek K, Vogl T, et al. Myeloid-related proteins 8 and 14 induce a specific inflammatory response in human microvascular endothelial cells. Blood 2005; 105: 2955-2962.

[38] Furukawa S, Matsubara T, Jujoh K, Yone K, Sugawara T, Sasai $\mathrm{K}$, et al. Peripheral blood monocyte/macrophages and serum tumor necrosis factor in Kawasaki disease. Clin Immunol Immunopathol 1988; 48: 247-251.

[39] Ritman EL, Lehman A. The dynamic vasa vasorum. Cardiovasc Res 2007; 75: 649-658.

[40] Scotland RS, Vallance PJ, Ahluwalia A. On the regulation of tone in vasa vasorum. Cardiovasc Res 1999; 41: 237-245.

[41] Masuda H, Naoe S, Tanaka N. A pathologic study of coronary artery in Kawasaki disease (MCLS): with special reference to morphogenesis of aneurysm [Myakkangaku, J Jpn Coll Angiol] 1981; 21: 899-912.

[42] Breier G, Albrecht U, Sterrer S, Risau W. Expression of vascular endothelial growth factor during embryonic angiogenesis and endothelial cell differentiation. Development 1992; 114: 521-532.

[43] Kai H, Kuwahara F, Tokuda K, Shibata R, Kusaba K, Niiyama $\mathrm{H}$, et al. Coexistence of hypercholesterolemia and hypertension impairs adventitial vascularization. Hypertension 2002; 39: 455-459.

[44] Dvorak HF, Brown LF, Detmar M, Dvorak AM. Vascular permeability factor/vascular endothelial growth factor, microvascular hyperpermeability, and angiogenesis. Am J Pathol 1995; 146: 1029-39.

[45] Heistad DD, Marcus ML, Martins JB. Effects of neural stimuli on blood flow through vasa vasorum in dogs Circ Res 1979; 45: 615-620.

[46] Hashimoto Y, Yoshinoya S, Aikawa T, Mitamura T, Miyoshi Y, Muranaka M, et al. Enhanced endothelial cell proliferation in acute Kawasaki disease (muco-cutaneous lymph node syndrome). Pediatr Res 1986; 20: 943-946.

[47] Sakata K, Kita M, Imanishi J, Onouchi Z, Liu Y, Mitsui Y. Effect of Kawasaki disease on migration of human umbilical vein endothelial cells. Pediatr Res 1995; 38; 501-505.

[48] Sakata K, Hamaoka K, Ozawa S, Niboshi A, Yahata T, Fujii M, et al. Matrix Metalloproteinase-9 in vascular lesions and endothelial regulation in Kawasaki disease. Circ J 2010; 74: $1670-1675$.
[49] Hotchi M. Pathologic concept of vasculitis. [in Japanese]. Jpn J Clin Med 1985; 43: 2017-2025.

[50] Onouchi Z. Echocardiographic diagnosis of coronary artery lesions in Kawasaki disease. In: Kawasaki T, Shigematsu I, Hamashima Y, Yanagawa H, Kato H, editors. Kawasaki Disease. Japan: Nankodo Publications, 1988: 178-185.

[51] Galili O, Herrmann J, Woodrum J, Sattler KJ, Lerman LO, Lerman A. Adventitial vasa vasorum heterogeneity among different vascular beds. J Vasc Surg 2004; 40: 529-535.

[52] Munro-Faure H. Necrotizing arteritis of the coronary vessels in infancy; case report and review of the literature. Pediatrics 1959; 23: 914-926.

[53] Amano S, Hazama F, Hamashima Y. Pathology of Kawasaki disease. II. Distribution and incidence of the vascular lesions. Jpn Circulation J 1979; 43: 741-748.

[54] Naoe S, Asaji A, Takahashi K, Masuda H, Tanaka N. Coronary artery lesions in children. Particular focus to the coronary artery aneurysm. [Byouri to Rinsho], Pathol Clin Med 1988; 6: 184-192.

[55] Ichinose E. Prognosis of coronary aneurysms due to Kawasaki disease: Search of risk factors using multivariate analyses. [Nippon Shonika Gakkai-Zasshi], J Jpn Pediatr Soc 1985; 89: 1595-1603.

[56] Ohmochi Y, Onouchi Z, Oda Y, Hamaoka K. Assessment of effects of intravenous dipyridamole on regional myocardial perfusion in children with Kawasaki disease without angiographic evidence of coronary stenosis using positron emission tomography and H2(15)O. Coronary Artery Dis 1995; 6: 555-559.

[57] Lavi S, Yang EH, Prasad A, Mathew V, Barsness GW, Rihal CS, et al. The interaction between coronary endothelial dysfunction, local oxidative stress, and endogenous nitric oxide in humans. Hypertension 2008; 51: 127-133.

[58] Onouchi Z, Hamaoka K, Ozawa S, Sakata K, Kiyosawa N, Ito $\mathrm{H}$. Neutropenia in the acute phase of Kawasaki disease and prevention of coronary artery aneurysm. Pediatr Int 2009; 51: 448-452.

[59] Kalogeris T, Baines CP, Krenz M, Korthuis RJ. Cell biology of ischemia /reperfusion injury. Int Rev Cell Mol Biol 2012; 298: 229-317.

[60] Huelmann WC, Dubelaar MI. Carnitine requirement of vascular endothelial and smooth muscle cells in imminent ischemia. Mol Cell Biochem 1992; 116: 125-129.

[61] Pachori AS, Melo LG, Hart MI, Noiseux N Zhang L, Morello F, et al. Hypoxia-regulated therapeutic gene as a preemptive strategy against ischemia/reperfusion tissue injury. Proc Natl Acad Sci U S A 2004; 101: 12282-12287.

[62] US patent 6630507. (https:/worldwide.espacenet.com/textdoc? DB-EPODOC\&IDX=US6630507), Hampson Aidan J, Axelrod Julius, Grimaldi Maurizio, "cannabinoids as antioxidants and neuroprotectants", issued 200310-07.

[63] Ahmed LA, Salem HA, Attia AS, Agha AM. Pharmacological preconditioning with nicorandil and pioglitazone attenuates myocardial ischemia/reperfusion injury in rats. Eur $\mathrm{J}$ Pharmacol 2011; 663: 51-58. 